\title{
Qualitative and temporal characteristics of electronic document management processes in cargo and commercial operations
}

\author{
Shokhrukh Kamaletdinov, and Nosir Tokhirov* \\ Tashkent State Transport University, Tashkent, Uzbekistan
}

\begin{abstract}
The article presents a methodology for determining quantitative indicators of the quality of documents of station commercial reporting SCR. The attributes of the document quality components are described. The relations between the documents are determined, while the direct and indirect relations for subsequent documents are revealed. To quantify the quality of the documents SCR proposed methodology consists of the following stages: determination of quality characteristics of documents SCR; determine the methods and procedures for measuring and evaluating the selected quality characteristics; quantitative assessment of quality characteristics using the proposed methods. To substantiate the adequacy of the research results based on the theory of a dynamic probabilistic loaded graph, a model of a dynamic probabilistic technological process is developed.
\end{abstract}

\section{Introduction}

It became obvious that the introduction of electronic document management in technological processes in organizations with a large volume of work has significant effects. On the railways of such countries as Russia, Ukraine and Belarus, electronic interaction between customers and carriers has been practiced for a long time. Studies have been conducted to prove the attractiveness of the use of electronic document management in terms of social significance and economic effect. In the scientific works of scientists I. A. Yelova [1], M. M. Kolos [2], and M. A. Potter [3] considers the issues of development of measures to improve the work of railway transport of the Republic of Belarus in the context of the use of electronic legal documents covering various aspects of the technology of freight and commercial work and also revealed the advantages of using electronic legally significant documents and implementation of forward-looking assessment of the effectiveness of electronic documents in freight and commercial work. However, these studies did not consider quantitative indicators of the quality of documents when filling out on electronic forms and on paper.

In the scientific works of Yu. I. Sokolov [4], A. A. Alferova [5], the issues of methodology and model for assessing the quality of transport services for cargo owners in railway transport are considered. But the issue of determining the methodology for

\footnotetext{
*Corresponding author: nosirtohirov@gmail.com
} 
determining the quality of documents involved in transportation processes is not considered.

In the articles of E. P. Bulavsky [6, 7], the issues of determining the quantitative indicators of technical documentation for railway automation and telemechanics devices are considered. The methodology is developed, and the qualitative characteristics of the technical documentation are calculated.

In the article [8], the processes of cargo planning and dispatch in composite document management are modelled. The advantages of electronic document management in terms of time characteristics of filling in and remote customer service are identified.

The analysis of the works presented above showed that the quality of the station commercial reporting documents was not evaluated by quantitative methods. The lack of quantifying the quality of SCR systems can cause an increase in defects in work, increasing the financial and time risks associated with cargo operations and transportation operations. Since on the railways of the Republic of Uzbekistan, the documents of the SCR, it is necessary to assess the feasibility of switching to electronic document management in terms of the quality of documents involved in the transportation process.

\section{Materials and methods}

Document quality SCR

All documents have attributes, i.e. properties that define the distinctive features of each of them. Thus, the total number of document properties involved in cargo and commercial processes is defined as the sum of the attributes of each document.

For each document, the standard deviation can be defined documents - predecessors or successors. A precursor document is a document from which this document is created, based on or using elements, attributes, and relationships. A sequence document is a document created based on or using the elements, attributes, and relationships of a given document [3; pp. 37-39].

The documents are created in accordance with the current filling technology. With a manual filling, the relationships between the documents of the predecessors and the followers are determined heuristically, so the probability of errors in this method is higher. With an automated filling, some of the links are strictly defined, and their accounting is carried out automatically by the software.

Figure 1 shows the relationships between the main types of SCR systems. The connectedness of the SCR documents is determined by the correspondence of the follower attributes to the attributes of the generating document.

The quality of the follower depends on the quality of its predecessors, from the corresponding reference data, and the level of use of information from the database. 


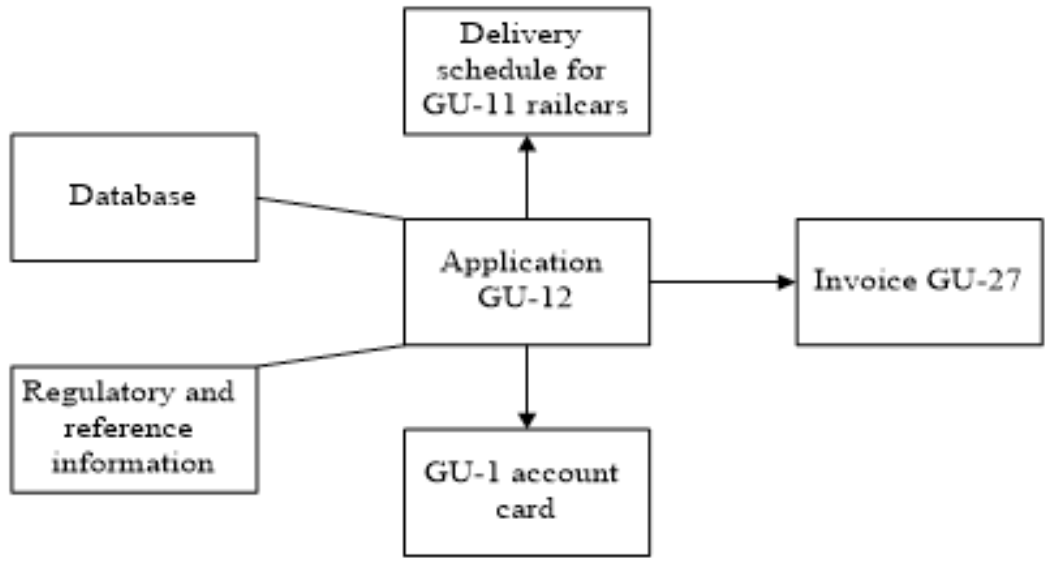

Fig1.1. The relationship between the documents of the station commercial reports

With an automatic filling, all the links, and automated filling, some are strictly defined. The software takes these connections into account automatically. Preparing and filling in the documents of the station commercial reporting system SCR under the control of specialized software should be under strict control to ensure high quality of transportation. The features of the automation systems for the preparation and filing of the SCR include the fact that the attributes strictly comply with the Rules of Cargo Transportation (RCT) and the instructions for maintaining station commercial reporting (IMSCR) [5].

Figure 2 the main attributes of the GU-12 application are shown.

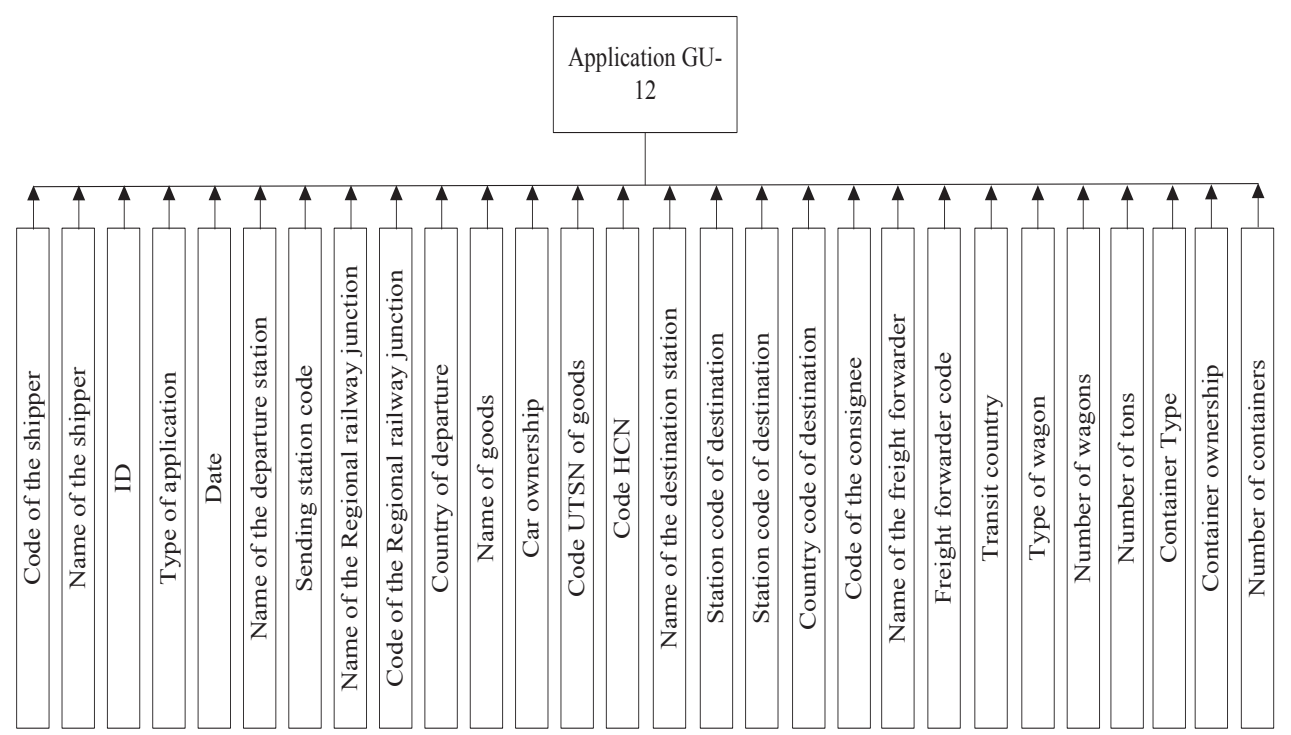

Fig.2. The attributes of the application GU-12

To assess the quality of the station commercial reporting documents, a methodology is proposed that consists of the following steps::

1. Determination of the quality characteristics of the station commercial reporting documents.

2. Definition of methods and order of measurement and evaluation of the selected ones. Quality characteristics. 
3. Quantitative assessment of quality characteristics using the proposed methods.

Determining the quality characteristics of station commercial reporting documents

The following indicators can describe the quality characteristics of the station commercial reporting documents (Fig. 3):

ease of obtaining information (the ability to obtain information from relevant sources);

connectivity between documents (matching the documents of the followers to the predecessors);

compliance with standards (compliance with the documents of the station commercial reporting rules of cargo transportation, international standards and regulatory and reference documents);

ease of perception of information.

The quality of the documents station business reporting

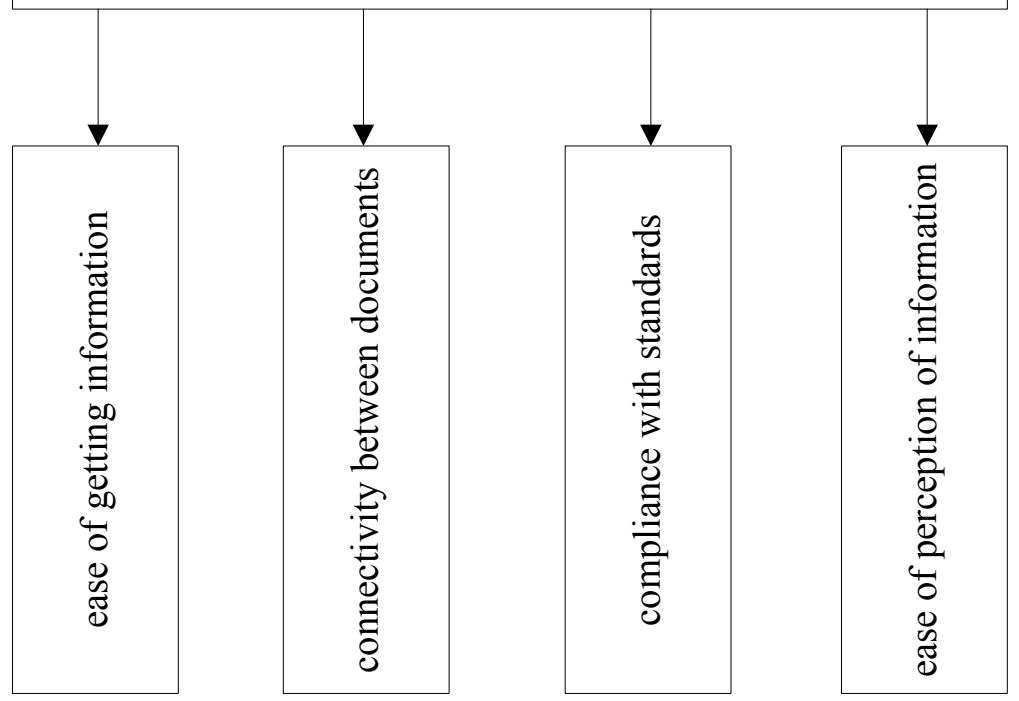

Fig.3. The quality characteristics of commercial documents, the station reporting

The convenience of obtaining information is understood as the availability and accessibility of the necessary instructions, references and tips for the correct execution of documents. In automated document processing systems, it is possible to obtain information from the corresponding database.

The connectedness between documents is understood as the correspondence of this document to the previous documents that are part of this transportation process. Simultaneously, the content of some determines the content of others, but this correspondence is not always unambiguous. Having direct links between documents makes it easier to verify their validity. The number of direct links between different documents is determined by the amount of information contained in each of them.

Under the standards refers to the conformity of the document SCR RCT IMSCR, international standards and normative references.

Ease of perception of information, it is fast processing of information, the level of fatigue of vision, the level of memorization of the necessary data. 


\subsection{Defining methods and procedures for measuring and evaluating selected quality characteristics}

The quality of the SCR documents can be represented on the basis of the description of the characteristics proposed above. Thus, the quality of the documents of the SCR system is described by the functional form:

$$
K_{d}=\left\{C_{y}, C_{c}, C_{c m}, C_{a}\right\},
$$

where, $\mathrm{C}_{\mathrm{y}}$-ease of obtaining information, $\mathrm{C}_{\mathrm{c}}$-connectivity of documents $\mathrm{C}_{\mathrm{cт}}$ compliance with standards, $\mathrm{C}_{\mathrm{a}}$-ease of perception of information.

We will perform a quantitative assessment of the characteristics of the transport documents as follows.

A quantitative assessment of the convenience of obtaining information can be determined by selecting the appropriate value described in Table 1 .

Table 1. Ease of getting information

\begin{tabular}{|c|c|}
\hline $\mathrm{C}_{\mathrm{y}}$ & The level of convenience of obtaining information \\
\hline $0.3-0.5$ & Low level of convenience \\
\hline $0.6-0.8$ & Medium level of convenience \\
\hline $0.9-1$ & High level of convenience \\
\hline
\end{tabular}

For electronic document management, $\mathrm{C}_{\mathrm{y}}=0.9$, since information about attributes can be obtained from auxiliary reference books and from the database in an automated or automatic way. Therefore, in the paper document flow, we accept $\mathrm{C}_{\mathrm{y}}=0.5$, since for paper documents, obtaining the necessary information can be quite time-consuming.

Connectedness is defined as:

$$
C=\frac{N_{c}}{N_{a}} \cdot \gamma
$$

where, $N_{c}$ is the number of attributes associated with previous documents, $N_{a}$ is the total number of attributes in the document, $\gamma$ is the coefficient of accounting for links between documents.

Since in the electronic document flow, the links will be taken into account automatically, it is advisable to take $=0.93$. In the paper document flow, the presence of previous documents will be required for the reconciliation of attributes; therefore, it is fair to accept $\gamma=0.65$.

We will determine compliance with the standards by selecting the values of the appropriate level from Table 2 .

Table 2. Compliance with standards

\begin{tabular}{|l|l|}
\hline \multicolumn{1}{|c|}{$\mathrm{C}_{\mathrm{cT}}$} & The level of compliance \\
\hline $0.3-0.5$ & Low level of compliance \\
\hline $0.6-0.8$ & Average level of compliance \\
\hline $0.9-1$ & High level of compliance \\
\hline
\end{tabular}

Electronic document management will include format and logical attribute control for compliance with the standards for this type of document. In paper document management, the correct completion of documents depends on the employee's qualifications or the shipper. From the above, we can estimate the degree of compliance with electronic document management standards as $C_{c m}=0.1$, and paper document 
management $C_{c m}=0.5$.

The convenience of information perception can be evaluated based on research by foreign scientists. According to American researchers, text from a computer screen (monitor) is perceived $25 \%$ slower than when reading from a sheet of paper, which must be taken into account when preparing documents [6]. Therefore, in the electronic document flow, $C_{a}=1$, and in the paper document flow, $C_{a}=0.75$.

\subsection{Quantitative assessment of quality characteristics using the proposed methods.}

The results of the expert assessment of seven different documents are summarized in Table 3. A graphical representation of the evaluation of the quality of documents SCR shown in Table 3-4. According to the proposed method, them shows the results of a quantitative assessment of the quality of the documents. The value of each of the quality characteristics is represented by a dot on the corresponding axis. The larger the area of the resulting quadrilateral, the higher the quality of the document Table 3.

Table 3 The results of the evaluation

\begin{tabular}{|c|c|c|c|c|c|c|c|c|}
\hline \multirow{2}{*}{ Documents } & \multicolumn{2}{|c|}{$\mathrm{C}_{\mathrm{y}}$} & \multicolumn{2}{c|}{$\mathrm{C}_{\mathrm{c}}$} & \multicolumn{2}{c|}{$\mathrm{C}_{\text {ст }}$} & \multicolumn{2}{c|}{$\mathrm{C}_{\mathrm{a}}$} \\
\cline { 2 - 9 } & Elec & Paper & Elec & Paper & Elec & Paper & Elec & Paper \\
\hline GU-12 & 0.9 & 0.5 & 0.27 & 0.19 & 1 & 0.5 & 0.75 & 0.5 \\
\hline GU-11 & 0.9 & 0.5 & 0.62 & 0.43 & 1 & 0.5 & 0.75 & 0.5 \\
\hline GU-1 & 0.9 & 0.5 & 0.36 & 0.25 & 1 & 0.5 & 0.75 & 0.5 \\
\hline GU-45 & 0.9 & 0.5 & 0.21 & 0.14 & 1 & 0.5 & 0.75 & 0.5 \\
\hline GU-46 & 0.9 & 0.5 & 0.44 & 0.31 & 1 & 0.5 & 0.75 & 0.5 \\
\hline FDU-92 & 0.9 & 0.5 & 0.23 & 0.16 & 1 & 0.5 & 0.75 & 0.5 \\
\hline GU-27 & 0.9 & 0.5 & 0.26 & 0.18 & 1 & 0.5 & 0.75 & 0.5 \\
\hline
\end{tabular}

Thus, the proposed structure of indicators makes it possible to quantify the quality of SCR documents and to model document flow processes. It provides the ability to submit requirements for documents in electronic form and makes it possible to compare options for the implementation of document management in freight and commercial work on railway transport.

\section{Results}

The study of temporal characteristics with the use of probabilistic dynamically loaded graph

A dynamic probabilistic loaded graph (DVNG) is called a directed graph $G=\left(X_{G}, P_{G}\right),\left(\left|X_{G}\right|=n,\left|P_{G}\right|=m\right)$, from which at any given time $\mathrm{t} \in \mathrm{T}$, for any vertices $x_{i}, x_{j}$ from $X_{G}$ 1-я дуга $U_{i j}^{(l)} \in P_{G}$ exists with probability $p_{i j}^{(l)}(t)$. If at a given time $\mathrm{t}$ is an arc $U_{i j}^{(l)}$ if there is, then it is characterized by a priori known value $C_{t}\left(U_{i j}^{(l)}\right)$ - arc load at time t [7; p. 48-57, 8;p. 45-56 ].

We introduce a definition: dynamic probabilistic process (DTP) is called dynamic probabilistic loaded graph process chain corresponding to the description of the workflow process and processing the set of transport documents are logically interrelated, functionally complete a sequence of operations. 
The adjacency matrix $A(G)_{[n \times n]}=\left\|a_{i j}\right\|$ it is called a square matrix of dimension $[n \times n], n=\left|X_{G}\right|$, each element $a_{i j}$ which is equal to the number of possible arcs (loops at $i=j$ )from the top $x_{i} \in X_{G}$ to the top $x_{j} \in X_{G}$

The probability matrix $\left.G=\left(X_{G}, P_{G}\right)\right)$ it's called the matrix $P_{G}(t)=\left\|\bar{p}_{i j}(t)\right\|$ dimension $[n \times n], n=\left|X_{G}\right|, \quad$ each element $\quad \bar{p}_{i j}(t)=\left(p_{i j}^{1}(t), p_{i j}^{2}(t), \ldots, p_{i j}^{\left(k_{i j}\right)}(t)\right)$, which is the probability vector of the existence of the corresponding arc from the vertex $x_{i} \in X_{G}$ to the top $x_{j} \in X_{G}$ at time t.

Ordered sequence of $\operatorname{arcs} U_{i_{1} i_{2}}^{l_{1}}, U_{i_{2} i_{3}}^{l_{2}}, \ldots, U_{i_{k} i_{k+1}}^{\left(l_{k}\right)}$ forms a possible path $\mu_{i_{1}, i_{2}, \ldots i_{k+1}}^{\left(l_{1}, l_{2}, \ldots l_{k}\right)}$ from the top $x_{i_{1}} \in X_{G}$ to the top $x_{i_{k+1}} \in X_{G}$, if there is such an ascending sequence of consistent time slices $\left(t_{i_{1}}, t_{i_{2}}, \ldots, t_{i_{k}}\right)$ what is the corresponding ordered sequence of probabilities $\left(p_{i_{1} i_{2}}^{l_{1}}\left(t_{i_{1}}\right), p_{i_{2} i_{3}}^{l_{2}}\left(t_{i_{2}}\right), \ldots, p_{i_{k} i_{k+1}}^{\left(l_{k}\right)}\left(t_{i_{k}}\right)\right)$ does not contain null elements.

In [7; p.48-57], definitions of the reliability and risk of the path for transport networks are given. We will formulate these definitions for document management processes in cargo and commercial work.

The reliability of the path $\mu_{i_{1}, i_{2}, \ldots j_{k+1}}^{\left(l_{1}, l_{2}, \ldots l_{k}\right)}$, corresponding to the start time of the movement $t_{i_{1}}$, the value is called $\Xi=\left(p_{i_{1} i_{2}}^{l_{1}}\left(t_{i_{1}}\right), p_{i_{2} i_{3}}^{l_{2}}\left(t_{i_{2}}\right), \ldots, p_{i_{k} i_{k+1}}^{\left(l_{k}\right)}\left(t_{i_{k}}\right)\right)$.

The risk of the path $\mu_{i_{1}, i_{2}, \ldots i_{k+1}}^{\left(l_{1}, l_{2}, \ldots l_{k}\right)}$, corresponding to the start time of the movement $t_{i_{1}}$ on value is called $\Psi=\left(1-p_{i_{1} i_{2}}^{l_{1}}\left(t_{i_{1}}\right), p_{i_{2} i_{3}}^{l_{2}}\left(t_{i_{2}}\right), \ldots, p_{i_{k} i_{k+1}}^{\left(l_{k}\right)}\left(t_{i_{k}}\right)\right)$.

The reliability and risk of each possible path are functions of the start time of the workflow processes $t$.

The optimal time to start moving along the path $\mu_{i_{1}, i_{2}, \ldots i_{k+1}}^{\left(l_{1}, l_{2}, \ldots l_{k}\right)}$ the time is called $t_{i_{1}}^{*}$, for which the reliability of this path is maximum (the risk is minimal). Consider two different vertices of the DVTP $x_{i_{1}}$ и $x_{i_{k+1}}$. Let $M_{i_{1} i_{k+1}}=\left\{\mu_{1}, \mu_{2}, \ldots, \mu_{s}\right\}$ - the set of all possible paths from $x_{i_{1}}$ в $x_{i_{k+1}}$. We will find the optimal start time for each path and, accordingly, the value of the maximum reliability of this path.

The path from the vertex $x_{i_{1}}$ to the top $x_{i_{k+1}}$ it is called one of the least risky paths if its maximum reliability is not less than that of other paths from $\left\{\mu_{1}, \mu_{2}, \ldots, \mu_{s}\right\}$. The passage time of this arc is selected as the arc loads. If a specific path from the vertex is fixed (select $x_{i_{1}}$ to the top $x_{i_{k+1}}$, then the sum of loads of the arcs of this path will give the travel time from $x_{i_{1}}$ in $x_{i_{k+1}}$.

Travel time from $x_{i_{1}}$ in $x_{i_{k+1}}$ on the way $\mu$ it is called a real non-negative quantity $\Delta t_{i_{1} i_{k+1}}^{\mu}\left(t_{i_{1}}\right)$, equal to the sum of loads of all the arcs of the given path.It is clear that the travel time depends on the start time of the movement.

In [9; p. 64-67], the principles of assessing the quality of transport documents are set out. We formulate the modelling problem as an estimate of the process execution time 
(Table 4), depending on the achieved quality of the document and the start time of the processes. Consider the process in Fig. 2.

An event is a moment that reflects a certain stage of the project, which is the moment when an individual work or group of works is completed, and a new work or group of works can be started. The event has no duration in time; it is considered that the event occurs instantly. The network allocates initial (initial) event that marks the beginning of the work (project initiation), and final (ending) means the completion of all works of this complex (project completion) [10].

Events on the network graph are represented by circles (graph vertices), and works are represented by arrows (arcs of the oriented graph), while fictitious works are usually represented by dotted arrows [27].

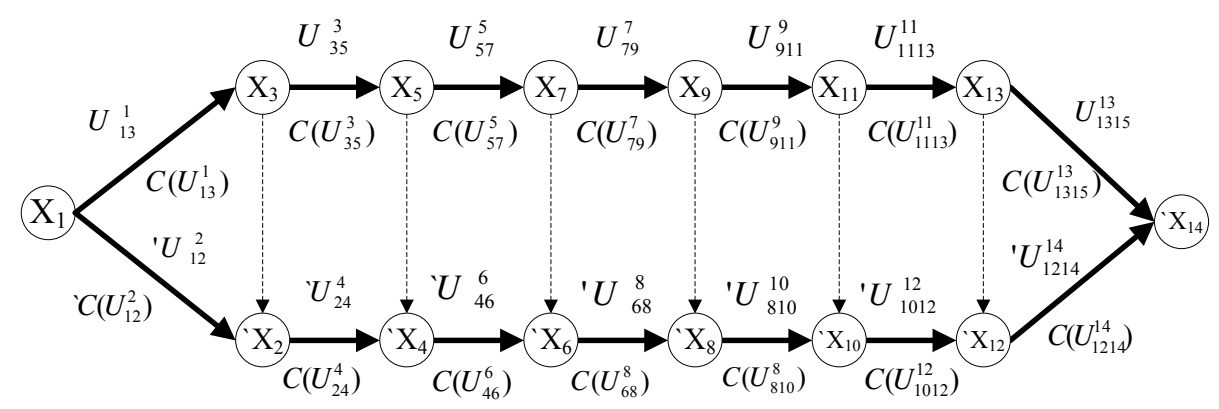

Fig.2. Dynamic probabilistic technological process

\section{Conclusion}

We introduce the following notation: $\mathrm{X}_{1} \div \mathrm{X}_{8^{-}}$process events $\Pi ; U_{i j}^{k}$ - an arc with the appropriate probability; $p_{i_{1} i_{2}}^{l_{1}} ; p_{i_{1} i_{2}}^{l_{1}}$ - the probability of a conditional transition depending on the quality of the station's commercial reporting documents; $C\left(U_{i j}^{(l)}\right)$ - arc load;

The adjacency matrix for the specified graph will have the form:

$$
A(G)_{[14 \times 14]}\left\|\begin{array}{llllllllllllll}
0 & 1 & 1 & 0 & 0 & 0 & 0 & 0 & 0 & 0 & 0 & 0 & 0 & 0 \\
0 & 0 & 0 & 1 & 0 & 0 & 0 & 0 & 0 & 0 & 0 & 0 & 0 & 0 \\
0 & 0 & 0 & 0 & 1 & 0 & 0 & 0 & 0 & 0 & 0 & 0 & 0 & 0 \\
0 & 0 & 0 & 0 & 0 & 1 & 0 & 0 & 0 & 0 & 0 & 0 & 0 & 0 \\
0 & 0 & 0 & 0 & 0 & 0 & 1 & 0 & 0 & 0 & 0 & 0 & 0 & 0 \\
0 & 0 & 0 & 0 & 0 & 0 & 0 & 1 & 0 & 0 & 0 & 0 & 0 & 0 \\
0 & 0 & 0 & 0 & 0 & 0 & 0 & 0 & 1 & 0 & 0 & 0 & 0 & 0 \\
0 & 0 & 0 & 0 & 0 & 0 & 0 & 0 & 0 & 1 & 0 & 0 & 0 & 0 \\
0 & 0 & 0 & 0 & 0 & 0 & 0 & 0 & 0 & 0 & 1 & 0 & 0 & 0 \\
0 & 0 & 0 & 0 & 0 & 0 & 0 & 0 & 0 & 0 & 0 & 1 & 0 & 0 \\
0 & 0 & 0 & 0 & 0 & 0 & 0 & 0 & 0 & 0 & 0 & 0 & 1 & 0 \\
0 & 0 & 0 & 0 & 0 & 0 & 0 & 0 & 0 & 0 & 0 & 0 & 0 & 1 \\
0 & 0 & 0 & 0 & 0 & 0 & 0 & 0 & 0 & 0 & 0 & 0 & 0 & 1 \\
0 & 0 & 0 & 0 & 0 & 0 & 0 & 0 & 0 & 0 & 0 & 0 & 0 & 0
\end{array}\right\|
$$

The probability matrix will look like 


$$
P(G)_{[14 \times 14]}=\left\|\begin{array}{cccccccccccccc}
0 & p_{12} & p_{13} & 0 & 0 & 0 & 0 & 0 & 0 & 0 & 0 & 0 & 0 & 0 \\
0 & 0 & 0 & p_{24} & 0 & 0 & 0 & 0 & 0 & 0 & 0 & 0 & 0 & 0 \\
0 & 0 & 0 & 0 & p_{35} & 0 & 0 & 0 & 0 & 0 & 0 & 0 & 0 & 0 \\
0 & 0 & 0 & 0 & 0 & p_{45} & 0 & 0 & 0 & 0 & 0 & 0 & 0 & 0 \\
0 & 0 & 0 & 0 & 0 & 0 & p_{56} & 0 & 0 & 0 & 0 & 0 & 0 & 0 \\
0 & 0 & 0 & 0 & 0 & 0 & 0 & p_{67} & 0 & 0 & 0 & 0 & 0 & 0 \\
0 & 0 & 0 & 0 & 0 & 0 & 0 & 0 & p_{78} & 0 & 0 & 0 & 0 & 0 \\
0 & 0 & 0 & 0 & 0 & 0 & 0 & 0 & 0 & p_{89} & 0 & 0 & 0 & 0 \\
0 & 0 & 0 & 0 & 0 & 0 & 0 & 0 & 0 & 0 & p_{910} & 0 & 0 & 0 \\
0 & 0 & 0 & 0 & 0 & 0 & 0 & 0 & 0 & 0 & 0 & p_{1011} & 0 & 0 \\
0 & 0 & 0 & 0 & 0 & 0 & 0 & 0 & 0 & 0 & 0 & 0 & p_{1112} & 0 \\
0 & 0 & 0 & 0 & 0 & 0 & 0 & 0 & 0 & 0 & 0 & 0 & 0 & p_{1213} \\
0 & 0 & 0 & 0 & 0 & 0 & 0 & 0 & 0 & 0 & 0 & 0 & 0 & p_{1313} \\
0 & 0 & 0 & 0 & 0 & 0 & 0 & 0 & 0 & 0 & 0 & 0 & 0 & 0
\end{array}\right\|,
$$

Table 4. The results of the calculations

\begin{tabular}{|c|c|c|c|c|}
\hline Ways & Arcs & $\begin{array}{c}\text { The appropriate } \\
\text { probability } \bar{p}_{i j}(t)\end{array}$ & $\begin{array}{c}\text { Reliability } \\
\text { of the path } \\
\Xi\end{array}$ & $\begin{array}{l}\text { Travel } \\
\text { time, min }\end{array}$ \\
\hline$\mu_{1}$ & $\begin{array}{l}U_{13}^{1}, U_{35}^{3}, U_{57}^{5}, U_{79}^{7}, \\
U_{911}^{9}, U_{1113}^{11}, U_{1315}^{13}\end{array}$ & $\begin{array}{c}0.73 ; 0.82 ; 0.75 ; 0.71 ; \\
0.77 ; 0.72 ; 0.73\end{array}$ & 0.13 & 31 \\
\hline$\mu_{2}$ & $\begin{array}{l}U_{12}^{2}, U_{24}^{4}, U_{46}^{6}, U_{48}^{8} \\
U_{810}^{10}, U_{1012}^{12}, U_{1214}^{14}\end{array}$ & $\begin{array}{l}0.55 ; 0.61 ; 0.56 ; 0.54 \\
\quad 0.58 ; 0.54 ; 0.55\end{array}$ & 0.02 & 87 \\
\hline$\mu_{3}$ & $\begin{array}{l}U_{13}^{1}, U_{24}^{4}, U_{46}^{6}, U_{48}^{8}, \\
U_{810}^{10}, U_{1012}^{12}, U_{1214}^{14}\end{array}$ & $\begin{array}{c}0.73 ; 0.61 ; 0.56 ; \\
0.54 ; 0.58 ; 0.54 ; 0.55\end{array}$ & 0.02 & 80 \\
\hline$\mu_{4}$ & $\begin{array}{l}U_{13}^{1}, U_{35}^{3}, U_{46}^{6}, U_{48}^{8}, \\
U_{810}^{10}, U_{1012}^{12}, U_{1214}^{14}\end{array}$ & $\begin{array}{c}0.73 ; 0.82 ; 0.56 ; \\
0.54 ; 0.58 ; 0.54 ; 0.55\end{array}$ & 0.03 & 75 \\
\hline$\mu_{5}$ & $\begin{array}{l}U_{13}^{1}, U_{35}^{3}, U_{57}^{5}, U_{48}^{8}, \\
U_{810}^{10}, U_{1012}^{12}, U_{1214}^{14}\end{array}$ & $\begin{array}{c}0.73 ; 0.82 ; 0.75 ; \\
0.54 ; 0.58 ; 0.54 ; 0.55 \\
\end{array}$ & 0.04 & 72 \\
\hline$\mu_{6}$ & $\begin{array}{l}U_{13}^{1}, U_{35}^{3}, U_{57}^{5}, U_{79}^{7}, \\
U_{810}^{10}, U_{1012}^{12}, U_{1214}^{14}\end{array}$ & $\begin{array}{c}0.73 ; 0.82 ; 0.75 ; \\
0.71 ; 0.58 ; 0.54 ; 0.55\end{array}$ & 0.05 & 72 \\
\hline$\mu_{7}$ & $\begin{array}{l}U_{13}^{1}, U_{35}^{3}, U_{57}^{5}, U_{79}^{7}, \\
U_{911}^{9}, U_{1012}^{12}, U_{1214}^{14}\end{array}$ & $\begin{array}{c}0.73 ; 0.82 ; 0.75 ; \\
0.71 ; 0.77 ; 0.54 ; 0.55\end{array}$ & 0.07 & 63 \\
\hline$\mu_{8}$ & $\begin{array}{l}U_{13}^{1}, U_{35}^{3}, U_{57}^{5}, U_{79}^{7}, \\
U_{911}^{9}, U_{1113}^{11}, U_{1214}^{14}\end{array}$ & $\begin{array}{c}0.73 ; 0.82 ; 0.75 ; \\
0.71 ; 0.77 ; 0.72 ; 0.55\end{array}$ & 0.10 & 46 \\
\hline
\end{tabular}

In this case, we can conclude that with a fully electronic document flow, the highest result is achieved in quality and time. 


\section{References}

1. Sokolov Yu. I. Product quality management in railway transport. Training manual, MIIT, p. 168. (2008).

2. Alferova, A. A. Assessment of the quality of transport services in railway transport.. Mandidate. dissert.: Moscow state University of Railway Transport (MIIT) MPS RF]. - Moscow. p 232 (2017).

3. Bulavsky P. E. Evaluation of the quality of technical documentation for JAT systems, Automation, communication, Informatics. 8. (2011).

4. Bulavsky, P. E., Markov, D. S., K. I. Kryuchkov, The impact of quality of technical documentation on the temporal characteristics of the process of electronic document management systems of railway automation, proceedings of Petersburg transport University, (1). (2013).

5. Instructions for maintaining station commercial reporting: The Ministry of communications of the USSR, fin. UPR. - Moscow : Transport, p 158 (1979).

6. Juler A., Dryuniani B. Creative strategies in advertising. - St. Petersburg: Peter,. p 384 (2002).

7. Orlov G. S. Dynamic probabilistic loaded graphs. Definitions, properties, areas of application, G. S. Orlov / / Bulletin of the Ryazan State Radio Engineering University.1 (31). - pp. 48-57. (2010)

8. Bulavsky P. E. Method for estimating the time of process execution and the adequacy of the simulation model of electronic document management of technical documentation Publishing house St. petersburg state University of Railway Transport, 2 pp. 45-56. (2014).

9. Aripov N. M., Kamaletdinov Sh. Sh. Assessment of the quality of documents of station commercial reporting on railway transport of the Republic of Uzbekistan, Transport: science, technology, management- 8 p 71. (2019).

10. . Pleskunov M. A. Problems of network planning: A textbook [Text]. M. A. Pleskunov. Yekaterinburg: Ural University Press,.p 92.( 2014),

11. Yelovoy I. A. Organization of cargo transportation using electronic documents, Monograph / Yelovoy I. A., Kotova Zh. I., Kolos M. M., Gonchar M. A. / Belarusian State University of Transport, 2017. p 170, (2017).

12. Kolos M. M., Gonchar M. A. Improving the technology of the Belarusian railway in the conditions of the use of electronic documents. 4.(2016).

13. Gonchar M. A. Improving cargo and commercial work on the Belarusian railway in the transition to electronic document management, Actual problems of science and technology through the eyes of young scientists: Materials of the International Scientific and Practical Conference. (2016).

14. Aripov N. M., Kamaletdinov Sh. Sh. Modeling of composite document management processes in freight and commercial operations of railways of the Republic of Uzbekistan on the basis of network planning and management, News of the TransSiberian Railway. 2. (2018).

15. Instructions for maintaining station commercial reporting: The Ministry of communications of the USSR, fin. UPR. - Moscow : Transport,.p 158 (1979)

16. Erofeev A. A. Information technologies in railway transport: textbook.method. manual-Gomel: Belarusian State University of Transport,.p 231.(2012).

17. Aripov N. M., Kamaletdinov Sh. Sh. Assessment of the quality of documents of station commercial reporting on railway transport of the Republic of Uzbekistan, Transport: science, technology, management. 8 p 71.(2019). 
18. Aripov N. M., Kamaletdinov Sh. Sh. Improvement of cargo and commercial work in the conditions of application of electronic document management in railway transport of the Republic of Uzbekistan, VESTNIK, Tashkent: TASHSTU, 2, pp. 39-45. (2018)

19. Levin B. A., Efimova O. V. Digital logistics and electronic data exchange in cargo transportation, World of Transport. 2017. 2 (69). pp. 142-149. (2017)

20. Technology of electronic document management in the registration of cargo transportation by rail, http// infotest.ru / info046. shtml-Accessed 11.11.2019.( 2019). 